\title{
Students as Practitioners in a Service Learning Context*
}

\author{
Jenifer K. McGuire Vernette Doty \\ Washington State University
}

\begin{abstract}
* Please address all correspondence to: Dr. Jenifer K. McGuire, Human Development Department, Washington State University, PO Box 644852, Pullman, WA 99164-4852, Phone: (509)335-2130; Fax (509)335-2456; Email: jkmcguire@wsu.edu
\end{abstract}

\begin{abstract}
This article describes a classroom and service learning approach to training students for careers in human services with adolescents. The approach incorporates the study of adolescent development, review of scholarly work, curriculum development, and direct work with adolescents. The course was designed for junior and senior undergraduates with specialized interests in the field of adolescent development, although the course design could easily be adapted to other populations. First we review the theoretical and empirical basis for the development of this combination of instructional strategies. Next we present a description of the course content and process. Finally, we examine student responses to and outcomes from the course.
\end{abstract}

Key words: Experiential education, Human services education, Mentoring, Peer led education, Student program leadership

Mentoring and teaching content can be powerful ways to enhance understanding and retention of course material for students (Amaral \& Vala, 2009); however, developing useful mentoring experiences that incorporate course content can be challenging in a university context. As such, this article focuses on the use of students as mentors to adolescents through the incorporation of family life programming within traditional undergraduate instruction. Specifically, we present a case example of an advanced adolescent development course where students had the opportunity to collaboratively develop and lead a prevention program curriculum for at-risk youth. The class was designed to provide an indepth study of adolescent development extending over an existing three-semester life course development sequence for students with a particular interest in adolescence. A careful review of peer-reviewed empirical research on adolescent development, and a translation of those concepts into practical elements of 
providing services to adolescents are fundamental components of this course. Service learning is employed as a way to provide services to the local community, while giving students the opportunity to implement the curriculum that they developed as part of the course. Here, we present the theoretical and empirical bases for using service learning, and in particular the strategy of mentoring, to enhance course understanding and application of course concepts. Finally, we present a case example illustrating the strategies employed, lessons learned, and evaluation of the reflective observations of the students.

\section{Kolb's Model of Experiential Learning}

Over the past several decades, Kolb and Kolb (2005) have developed and refined models of experiential learning that argue for the balance of content and experience alongside reflection and action. The goal of adult learners, they argue, is to become integrated into the profession by developing an ability to access both components of each these dialectic processes. Integrated learning, that which combines experience with conceptualization, has been found to improve adaptive flexibility to both experience based and concept based learning situations (Mainemelis, Boyatziz, \& Kolb, 2002). Complementary dialectics balance the tension between conceptualization and experience with the tension between reflection and action. Individuals with learning styles that balance these dialectics have been found to have improved flexibility, and thus, are viewed as more sophisticated learners (Mainemelis, et al., 2002). Transactions between the individual and the environment establish and maintain learning styles (Kolb and Kolb, 2005). Accordingly, the duty of education would be to provide transactions that facilitate the development of balanced learning strategies. Service learning, which typically incorporates reflection, is an educational strategy that promotes experience to complement academic concepts, and reflections that situate actions in a social and academic context. Thus providing service learning experiences that integrate active reflection has the potential to stimulate more sophisticated learning for students.

Using Kolb's model of experiential learning (Kolb and Kolb, 2005), Ethridge and Branscomb (2009) chronicled the active learning processes of children and adults by having university students implement an anti-bias curriculum with young children. Service learning is grounded in experiential learning, and provides a natural opportunity to use experiential education to expand on course information and use advanced cognitive skills. In fact, experiential education has been found to be an important component of guidance and teaching personal skills and development (Roaten \& Schmidt, 2009). When students develop experiential activities they learn the value of using such a strategy and become comfortable with experiential processes. Students in Ethridge and Branscomb's (2009) study reported that development and leadership of experiential anti-bias program sessions helped to facilitate not only their understanding of the content but also the process of active learning for students, and reflection on their own biases. In this paper, we describe a particular type of service learning, similar to that utilized by Ethridge and Branscomb (2009). University students used the academic content of a course to develop and then 
lead experiential workshops for high school students in the content of adolescent development. In this way, service learning incorporates community service with academic content while including process activities (e.g. preflection and reflection) to facilitate student learning and understanding of both course concepts and broader social justice issues.

\section{Mentoring to Enhance Understanding of Content and Process}

Teaching content, or rather mentoring other students in their learning of content, is associated with enhanced learning for students (Amaral \& Vala, 2009; Benware \& Deci, 1984). Teaching content can serve the dual purposes of solidifying academic content while at the same time promoting development of the process of leadership, curriculum development, and educational strategy. For example, in one study, students who served as mentors in a mentoring program showed improvements in mastery of the chemistry content. Students who were deemed underprepared at the beginning of a course and then later acted as mentors performed higher in a subsequent chemistry course and were more likely to be retained in the chemistry sequence compared to students without mentors or students who were not deemed underprepared, even while controlling for math SAT scores (Amaral \& Vala, 2009). Several other studies have documented increases in content learning when students expect to have to teach material, (Benware \& Deci, 1984), and self reported improved understanding when they participate as mentors (Gafney \& Varma-Nelson, 2007). When students are required to develop and lead material for others, they also are confronted with the task of developing a stronger understanding of the processes involved in leadership. For example, Garcia and Roblin (2008) found that when students engaged as active participants in curriculum development, they benefitted through enhanced critical thinking, and developed supportive professional relationships with other members of the curriculum development team. Mentoring programs often encourage mentors to engage with a mentee, providing support and guidance over a period of time. Leadership of an activity does not require the same long term commitment as mentoring; however, in this project, we asked students to engage with the youth using mentoring (i.e. providing support and guidance) throughout the weekend, not just when they were leading their own session.

Levels of mentoring. University-community partnerships that involve students as mentors to community youth afford the opportunity for many levels of mentoring. Community youth are mentored both by university students and indirectly by those who mentor the students. For example, students may receive mentoring from university faculty, service learning professionals on campus, and community partners. In turn, university faculty and community partners have the opportunity to share in peer mentoring and to be mentored by service learning professionals on campus. For example, the instructional faculty can learn from the professionals in the service learning field and from the professionals in the community with whom they collaborate. The community and service learning professional could benefit from contact with university faculty as well by having 
the opportunity to discuss current research and program practices. Individuals at all levels have the opportunity to benefit from the multiple relationships involved in collaborative partnerships.

Benefits to youth mentored. The benefits of receiving mentoring are well established in the literature (e.g., Mills, Heyworth, Rosenwax, Carr, \& Rosenberg, 2009; Torres Campos et al., 2008). In particular, several studies have documented the benefits to youth in community settings who are mentored by university students (Radcliffe \& Stephens, 2008; Koerner \& Harris, 2007). Using a quasiexperimental design with random assignment, Radcliffe and Stephens (2008) linked mentoring from college students to improvements in at-risk middle school students' perceptions of college, goals to attend college, and motivations to write. In their program, college students visited the middle school for tutoring and other mentoring activities to create a college culture.. Specific to the mentoring component, college students were each paired with one or two middle schoolers for mentoring and academic support. Additionally the college students hosted a college visit with a writing marathon for the youth. Likewise, Koerner and Harris 92007) found that community youth who were mentored by university students reported increased engagement in the formal schooling process, and Cooper (2002) described mentoring as a bridge to college. Taken together, mentors act as cultural brokers, providing career mentoring that can foster a sense of future and promote the importance of college going culture, beliefs, and values.

Benefits to student mentors. University students also benefit from formalized mentor programs designed for minority students (Torres Campos et al., 2008) or designed around certain academic departments (Amaral \& Vala, 2009; Mills, et al., 2009). For example, education students who participated in a pre-service mentoring program with community youth showed greater retention in education programs and student teaching (Koerner \& Harris, 2007). The value of community partners mentoring of university students has received less attention; however, research suggests enhanced collaboration and reflective guidance among mentored students (Branyon, 2008). Students also can benefit from peer mentoring and cohort development that occurs when a group of students participate jointly in a service project (Branyon, 2008). Finally, the mentoring, structure, and support that comes from the university faculty and service learning professionals is related to greater mentor retention and satisfaction (Koerner \& Harris, 2007).

Studies of high school students who act as mentors or program leaders have found similar benefits for the students (Lazerson, Foster, Brown, \& Hummel, 1988; Strange, Forrest, \& Oakley, 2002; Wright \& Borland, 1992). For example, Lazerson and associates (1988) examined the impact of a tutoring program on adolescent (middle school) tutors. All tutors were deemed in classified need of special education for learning disabilities and had an excessive tardiness or truancy problem. Tutors worked individually with younger LD (learning disabled) students over a six-week period. Tutors experienced growth towards a more internal locus of control, and a decrease in the number of 
truancies and tardy class periods per week. Wright and Borland's (1992) study examined the effects on early adolescents of mentoring younger students over a summer session. All students and mentors were identified as potentially academically gifted, ethnic minorities, economically disadvantaged, and living in New York City. Informal evaluations revealed satisfaction with the amount of learning and opportunity to make a difference that the mentors experienced. Strange and associates (2002) examined youth who were peer mentors for a sex education program and found increased knowledge about contraception, more acceptance of other people's opinions, increased comfort discussion sexuality, and a reported belief that the experience would help with future career development and life outside of school. The benefits of acting as a mentor for knowledge, career and personal development appear to exist across the range of adolescence including young adulthood.

\section{Mentoring to Enhance Professional Preparation}

Mentoring can support students in their professional development both by providing a service experience that mimics later potential professional opportunities and by allowing students to show leadership in ways that stimulate personal and professional growth. In one study, college student mentors who learned about their own teaching dispositions developed self affirming conclusions about their abilities, a better understanding of the needs of students, and improved self-efficacy (Koerner \& Harris, 2007). Another study found that students were able to uncover and reflect on their own biases. In teaching material students integrated the personal content themselves and came to recognize that they were teaching life lessons that they themselves needed to learn (Ethridge \& Branscomb, 2009). Program leadership provides an authentic learning experience that has been associated with better preparedness for later practicum experiences, particularly with a stronger understanding of how university topics are related to work with youth (Koerner \& Harris, 2007).

\section{Case Example}

In the following case example, we consider the design and implementation of an experientially-based approach to teaching an advanced adolescent development course. Experiential processes occurred in the classroom in the types of learning strategies, as well as through an integrated service learning project developed and implemented over the course of the semester. Students developed and implemented an experientially- and empirically-based prevention program curriculum to at-risk youth in the local community.

To illustrate the use of mentoring as a teaching device within a university class context, we present the case example of a class in Advanced Adolescent Development, offered in a human development program at a land grant university. This class is an upper division course open to Human Development majors who have completed the first 2 semesters of the 3 semester sequence in lifespan development, have junior or senior standing, and are working toward completion of a specialized certificate in Adolescence or Family Relations. The course is 
capped at 20 students, meets once weekly for 3 hours, and is taught by a faculty member with a research background in adolescent development.

Advanced Adolescent Development was designed to delve deeper into research about the human service needs of adolescents. Because students previously had covered primary concepts of adolescent development (e.g., physical development, identity, social networks), there was considerable latitude in the course design to focus on specific issues relevant to the current group of students. As such, a fundamental component of the course was student leadership in designating some course content. In prior years, students were responsible to develop lessons, choose readings and lead class 1-2 hours per semester on topics of their choosing. For the current course, we decided to formalize the lesson planning to incorporate experiential learning, and to have the students lead the developed curricula to a group of younger adolescents, after practicing with their peers. For example, one student chose "social identity development" as her research topic. She reviewed five empirical articles and wrote a literature review. One of those articles was chosen to be read by the entire class on the week she presented her program session. During her session, she had youth engage in an activity that used visual cues (a lesson from the brain development week) to explore social identities. The youth described the different social identities they encountered, and drew visual depictions of each, focusing on the specific visual cues of different groups.

The strategy of incorporating experiential processes and leading the sessions to younger youth met goals from prior years of having students delve into research, and teach that research to peers. However, the addition of the experiential content to be provided for younger adolescents allowed the incorporation of two new goals. First, students needed to review empirical research for what it offered to practitioners in the field and learn to extract the findings that would be useful in working with adolescents. Second, students developed some of the human services skills of program planning and implementation. With the prior model, student-led classes often took the form of short lectures that did not particularly engage fellow students. With the expectation of leading the program to adolescents, the accountability for making lessons more engaging increased and required greater investment from students.

To develop lessons, students engaged in a research literature review. They obtained the five most similar empirical, peer-reviewed journal articles they could find in order to isolate a specific research finding that appeared to have some convergent validity from multiple studies. Topics were varied including studies comparing visual processing to traditional decision making models in adolescent risk taking, or the role of exercise in promoting healthy body image for youth. From the research papers, activity ideas were generated that could engage youth to understand the main research findings within the topic. For example, one student who found studies documenting adolescents' beliefs about peers' sexual behavior chose an activity that asked youth to estimate how many youth were doing different sexual acts, and then shared the research based estimates to reveal misconceptions. Each of the major components of the lesson had to be based in 
research findings, and had to use experiential processes to engage and inform the youth.

Throughout the semester, students taught their lesson to their classmates when their topic area became current in the course. This trial run served to educate the class on each of the content areas, and as a chance to work out potential problems in teaching the class to youth. In most cases, students had developed more content than they would have time to present with the youth, thus allowing classmates an opportunity to help decide which elements of the lesson were most useful. Each student determined at least one of the several readings for the class session they led. Students were quizzed at the beginning of each class session on the readings for that week to ensure that they were prepared with the background knowledge necessary to support their classmates in fine tuning curriculum sessions. The weekly quizzes served as an important tool for accountability in learning the content of the research.

As a group, the students determined the order and content of the prevention sessions they had planned. The students chose a retreat environment that would provide programming on Friday afternoon/ evening and all day Saturday, and planned most of the practical aspects of hosting the weekend. A committee planned the menu and food preparation needs. Another committee wrote letters to local merchants asking for food or financial donations. One committee was responsible for compiling curriculum notebooks with all of the final sessions included. Other committees organized communication, transportation, and time management strategies to use during the retreat. Any aspect of the retreat that could physically be managed by students was.

Youth participants were recruited via the county juvenile services program. This program provides services for youth defined as at-risk, truant, or in probation or diversion programs. The director of juvenile services contacted eligible youth and offered them the opportunity to participate. Youth received credit for community service hours for participation in this program.

\section{Evaluation}

Although we did not conduct a specific evaluation, the students completed preflection and reflection writing exercises. From those, we coded the overall themes and describe those here. We supplement the primary themes with exemplar quotes from students. The overall response of the students was quite positive to the experience, although some needs for changes were identified as well. There were four main shifts in the content from the preflection to the reflection. First, at the preflection, 10 of the 14 students made comments that projected stereotypical views of adolescents, and in particular adolescents defined as at-risk. An example of this sort of comment is, "I hope they will realize that there are much better choices that they can make in life." By the reflection, only one student included a comment reflecting stereotypical views.

Second, at the preflection, students described the opportunity to teach as a chance to dispense content and "lecture to them." By the reflection, student comments were focused much more on the connection to the youth and the opportunity to stimulate their interest. Seven students had comments that shifted 
from "disseminating content" to "connecting." For example, some students stated, "I really enjoyed talking to each and every kid that was a part of this experience," "I learned to relate to that group" and "The kids really opened up to us."

Third, preflections and reflections revealed a desire for the retreat to assist in the development of professional goals, and its success in doing that. Several students described that the retreat helped them to realize that they really wanted to work with this age group and this population, while one student realized she would rather work with a less at-risk population. Finally, the students described areas of personal and group growth. Seven students commented specifically on the power of the group process such as "our class really came together as a group," and "we became closer and supported each other."

Informally, several themes emerged from discussions with students over the course of the following semester. First, students reported greater engagement with the course content because of the experiential and student driven elements of the course. They reported that they tried harder, read more, and learned more than in other sorts of classes. Second, students reported a greater understanding of their own professional development needs and were able to reflect more thoughtfully on the types of professional experiences they would like to pursue. Some students indicated that they would like to work with at-risk youth professionally, while others realized that they may be more suited to younger or less at-risk populations. Universally, they were more able to reflect on the planning, management, and personal leadership skills they would need in order to pursue careers working with groups of adolescents. Several of the students reported using the resources they had developed in class during their internships the following summer. Finally, the students reported an enhanced connection to their peers and to the academic department. For some students the foundations of collaborative professional relationships were developed during this semester.

\section{Future Directions}

As we (the instructor and the academic coordinator for the campus Center for Civic Engagement) reflect on the development and implementation of this course, we find places that this course experience can guide further investigations into service learning and mentoring, and places where the existing research indicates potential course improvements. Two issues stood out as future directions for research in service learning that could be informed from evaluations of a course such as: a) program leadership as a form of mentoring, and b) leading programs as a way to educate students on process and not just content. Course improvements suggested by the existing literature include increased involvement of community partners in the development and planning of the program, mentors, examination of outcomes for the youth participants, measurement of changes in student engagement within the department, and inclusion of professional development goals in the course design.

The existing research on students as mentors tends to focus either on individual tutoring or big brother/ sister type mentoring (Koerner \& Harris, 2007) or on student teaching of classroom content (Amaral \& Vala, 2009; Benware \& 
Deci, 1984; Radcliffe \& Stephens, 2008). Research examining the mentoring role of students who participate in nonacademic programs with groups of youth would help to inform educators who prepare students for careers in human services. Some studies have suggested that youth benefit from the change in the culture of college expectations (Koerner \& Harris, 2007; Radcliffe \& Stephens, 2008), but those studies are based on youth who had longer term direct contact with the same students. The benefit of shorter term contact, with less opportunity for significant relationship development, has not been established in the literature.

The course was designed not only to teach content but also to reinforce processes of learning for the students. An explicit examination of learning experiential processes and learning to glean program relevant data from research would help us to better understand the value of the course. The literature on the development of process versus the understanding of content for student mentors is limited, and largely an anecdotal aside to the studies of content learning (Ethridge \& Branscomb, 2009; Koerner \& Harris, 2007). Students learn more if they are able to implement new processes and show changes in professional development than if they simply absorb and integrate knowledge about adolescent development. In particular, research on adolescent development is yielding new information at a rapid pace, and the ability to review and integrate that information could be more useful in the long run than simply knowing the current state of research.

Finally, there are several changes to the course and evaluation of the course that can be made based on current findings in the literature. Community partners could provide significant learning opportunities for students (Branyon, 2008). Current research on community-university partnerships suggest that using a centralized system for the management of student service learning enhances the perceived ability of community partners to participate (Vernon \& Foster, 2002 ). In this course, the community partners' contact with the students was fairly minimal and restricted mostly to during the program itself. Expansion of the community partners' roles to include interaction with students in planning and evaluating the program could provide an important link for the students and help to solidify investment from the community partners in the project. Our evaluation efforts focused only on student preflection and reflection writing exercises. While those illuminate important processes, the course would be improved by the incorporation of an overall evaluation of both the students and the youth participants that extends beyond the scope of the course. To better understand the value of this strategy for the major and the community, we could incorporate several evaluation activities. First, we could track students in the course as they complete their internships and take positions to see how many of them accept positions in the field of adolescent development. We could interview prior course participants about the impact of this service experiences in their choice of internship and jobs. Finally, we could compare internship supervisor evaluations for this group to other groups of students in the major who did not participate in service learning experiences to see if they are rated as more prepared for their internships. With regard to the youth participants, we could interview prior participants about their experiences with the program, and we could track 
participants for time to completion of overall probation activity requirements as compared to probation youth who did not participate. Each of these strategies would provide useful evaluation data about the potential impacts of this strategy on the department and the local community.

\section{Conclusion}

To supplement the curriculum for an advanced adolescent development class, we provided students with the opportunity to develop an applied prevention program based on their reading of the current empirical literature on adolescent development. The program sessions were developed and pilot tested within the classroom. The resultant prevention program was implemented with youth from the county juvenile services program which provides programs for youth with probation or diversion requirements. Students in the class responded to the experience with written preflections and reflections that revealed areas of growth, including a shift away from stereotypical images of adolescents, an opportunity to gain new skills and experience, a shift away from viewing teaching as dispersing content to viewing teaching connecting students to ideas, and finally an experience of the power of group collaboration.

\section{References}

Amaral, K. E., \& Vala, M. (2009). What teaching teaches: Mentoring and the performance gains of mentors. Journal of Chemical Education, 86, 630633.

Benware, C. A., \& Deci, E. L. (1984). Quality of learning with an active versus passive motivational set. American Educational Research Journal, 21, $755-765$.

Branyon, J. (2008). Using mentoring and cohort collaboration: Enhancing teacher quality in pre-service teachers. The Delta Kappa Gamma Bulletin, Spring, 35-38.

Cooper, C. R. (2002). Counselors, mentors, and peers in the Puente Project: Five bridges along students' pathways to college: A developmental blueprint of families, teachers. Educational Policy, 16, 607-622.

Ethridge, E. A., \& Branscomb, K. R. (2009). Learning through action: Parallel learning processes in children and adults. Teaching and Teacher Education, 25, 400-408.

Gafney, L., \& Varma-Nelson, P. J. (2007). Evaluating peer-led team learning: A study of long-term effects on former workshop leaders. Journal of Chemical Education, 84, 535-539. 
Garcia, L. M., \& Roblin, N. P. (2008). Innovation, research and professional development in higher education: Learning from our own experience. Teaching and Teacher Education, 24, 104-116.

Koerner, K., \& Harris, J. (2007). Inspired learning: Creating engaged teaching and learning environments for university and school students through university to school mentor programs. International Education Journal, 8, 354-364.

Kolb, A. Y., \& Kolb, D. A. (2005). Learning styles and learning spaces: Enhancing experiential learning in higher education. Academy of Management Learning \& Education, 4, 193-212.

Lazerson, D. B., Foster, H. L., Brown, S. I., \& Hummel, J. W. (1988). The effectiveness of cross-age tutoring with truant, junior high school students with learning disabilities. Journal of Learning Disabilities, 21, 253-255.

Mainemelis, C., Boyatzis, R. E., \& Kolb, D. A. (2002). Learning styles and adaptive flexibility: Testing experiential learning theory. Management Learning, 33, 5-33.

Mills, C., Heyworth, J., Rosenwax, L., Carr, S., \& Rosenberg, M. (2009). Factors associated with the academic success of first year Health Science students. Advances in Health Sciences Education, 14, 205-217.

Radcliffe, R., \& Stephens, L. C. (2008). Preservice teachers are creating a college culture for at-risk middle school students. Research in Middle Level Education Online, 32, (4), 1-15.

Roaten, G. K., \& Schmidt, E. A. (2009). Using experiential activities with adolescents to promote respect for diversity. Professional School Counseling; 12, 309-314.

Strange, V., Forrest, A., \& Oakley, A. (2002). Peer-led sex education characteristics of peer educators and their perceptions of the impact on them of participation in a peer education program. Health Education Research, 17, 327-337.

Torres Campos, C. M., Phinney, J. S., Perex-Brena, N., Kim, C., Ornelas, B., Nemanim, L., Padilla Kallemyn, D. M., Mihecoby, A., \& Ramirez, C. (2008). A mentor-based targeted intervention for high-risk Latino college freshmen: A pilot study. Journal of Hispanic Higher Education, 8, 158178. 
Vernon, A., \& Foster, L. (2002). Nonprofit agency perspectives of higher education service learning and volunteerism. Journal of Nonprofit \& Public Sector Marketing, 10, 207-230.

Wright, L., \& Borland, J. H. (1992). A special friend: Adolescent mentors for young, economically disadvantaged, potentially gifted students. Roeper Review, 14, 124-129. 